\title{
Parametric Studies on Drill String Dynamics Drill mud damping effects with drive speed variation
}

\author{
Mohammed AlQaradawi, Meryem Kanzari , Balachandran Balakumar
}

\begin{abstract}
Complicated behavior of oilwell drill string with both torsional and lateral whirl vibrations are explored numerically and experimentally within this paper. A modified Jeffcott rotor model with attention to drill string and outer shell interactions is developed. Drill mud drag forces within a thin annular film surrounding the vibrating rotor are considered. With respect to the rotation speed drill mud damping effect on drill string behavior is studied. Numerical efforts are compared to experimental studies conducted with laboratory scale drilling system. The results obtained suggest that the drill mud dynamics are highly related to the drive speed and rotor deflection. The findings of this work are relevant to the understanding of hydrodynamic mass of drill muds on drill string dynamics and schemes for controlling them.
\end{abstract}

Keywords-drill string dynamics, drilling mud, modified Jeffcott rotor, lateral whirl.

\section{Introduction}

Drilling system are used in the exploration of fossil fuelscoal and natural gas. Long slender rotating structure called drill string is supported by the top drive, which rotates the drill string at the surface to drive the bit and allow the drill string to advance in the downhole. Iinteractions between drill bit and surrounding rock are reduced with the injection of a drill fluid, called also drill mud, which flows through the drill string and then pumped through nozzles in the bit. During drilling process, drill mud carries the cuttings back to the surface through the annulus between the wellbore and the drill string. Drilling fluids have a damping effects which can contribute to the structure stability.

Mohammed AlQaradawi

Department of Mechanical and Industrial Engineering, College of Engineering, Qatar University

Doha 2713, Qatar

Meryem Kanzari

Department of Mechanical and Industrial Engineering, College of Engineering, Qatar University

Doha 2713, Qatar

Balachandran Balakumar

Department of Mechanical Engineering, University of Maryland, College Park Maryland, USA
Prior efforts [e.g., 1] proved the efficiency of the mud in the drilling process by removal of cut materials from the hole, cool and lubricate the bit, maintain well bore stability, and help manage the contact between the drill pipes and well bore.

Typical Drillstring is illustrated in Fig.1. As shown, the Bottom hole Assembly (BHA) is comprised of two sections: the drill collar and the drill bit .

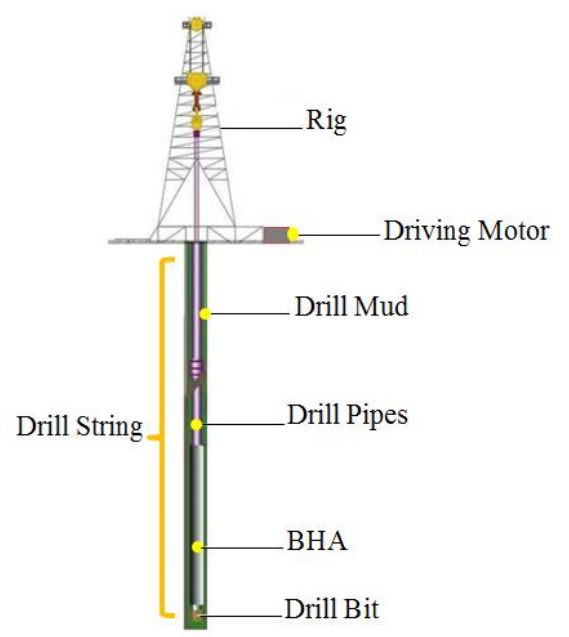

Figure 1. Illustration of rotary drilling system

The BHA is subjected to coupled lateral and torsional vibrations which are large in amplitude and can be very violent and harmful for the entire drilling structure. New challenges for experts to investigate the parameters and phenomenon enhancing drilling vibration and affecting drilling costs. Before the 1960's, research efforts were focused on the drillstring' s material strength components, the challenges have since changed to emphasize on its dynamic behavior [2]. An extensive number of prior efforts have been devoted to understand drill string nonlinear vibrations [3-7]. Control strategies appeared to mitigate drill string vibrations such as manipulating the top rotary system in soft manner, and thus, helping the absorption of torsional harmful waves at the surface. This solution has been used in different drilling wells and it has significantly reduced the bit stick-slip oscillations [8].

Other limited efforts have been focused on drill mud formulation and rheological behaviour, however, the influence of the mud on the contact nature between drill bit and borehole has not been reported. Drill mud is assumed as a constant viscous damping parameter [9] or as an active damping 
system. Jansen [10] and Cull [11] considered the effect mud damping with top end damping to reduce drill string vibrations. Damping forces from hydrodynamic drag has been modelled by Zhao et al. [12]. The effect of the drilling fluid, and its rheological properties, on drill string behaviour was not focused.

A study of drill mud rheological properties on whirling dynamics has been carried out in the author's group [13]. Here, building on this recent work, the authors examine the influence of drive speed on damping effect of drill mud on the system dynamics.

In this paper, drilling system is modelling as a three degree of freedom Jeffcott rotor subjected to continuous contact with stator. The rotor is supposed to be surrounded by annular drill mud. Analytical and numerical model of the proposed system is presented in section.2. Next, Simulation results are compared for different parameters and presented in Section.3. Subsequently, numerical predictions are compared with the experimental results. Cconcluding remarks are collected in the last section.

\section{Modified Jeffcott Rotor Description}

A rotor with diameter $D r$ and mass $m_{r}$ is assumed to represent the Bottom Hole Assembly. A stator with a clearance $\delta$ is presenting the borehole. A schematic of Jeffcott rotor -stator capable of torsional vibration is illustrated in Fig.2. The mass moment of inertia of the rotor is the quantity $J r$. Rotor is supposed to be symmetrical, lateral stiffness have an equivalent spring constant $k_{x}=k_{y}=k_{l} . K$ is the torsion stiffness. Similarly, the equivalent damping coefficient is $c_{x}=c_{y}=c_{1} . \mathrm{C}$ is the torsional damping coefficient.

Torsional deformation is given by $\Theta$, presented by the angle between $\mathrm{u} 1$ and $\mathrm{v} 1$. Rigid body rotation is limited by $\mathrm{v} 1$ and $\mathrm{w} 1$. To simplify the notation, the superposition of both $\Theta$ and $\Omega \mathrm{t}$ is named $\beta$.

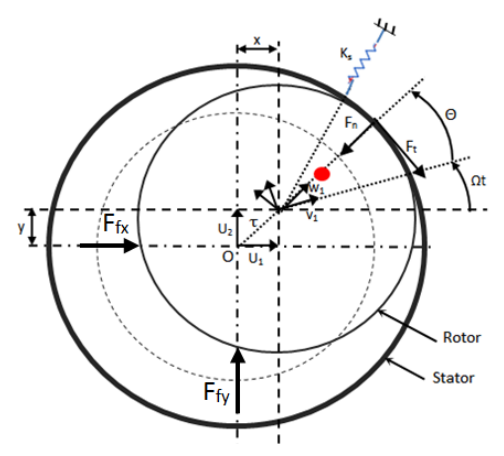

Figure 2. Dynamic state of the extended Jeffcott rotor model
Following along the lines of Ref. [14]Error! Reference source not found. the Kinetic Energy is written as:

$T_{\text {rotor }}=\frac{m_{r}}{2}\left(\dot{x}^{2}+y^{2}\right)+\frac{m}{2}\left((\dot{x}-e \dot{\beta} \sin \beta)^{2}+(\dot{y}-\right.$ $\left.e \dot{\beta} \cos \beta)^{2}\right)+\frac{j_{r}}{2} \beta^{2}$

The elastic potential energy can be written as:

$U=\frac{1}{2}\left(k_{1} x^{2}+k_{1} y^{2}+k \Theta\right)$

(2)

Using Hamilton's principle applied for deformable bodies, the simplified parametric equations of motion may be expressed as follows:

$\ddot{x}=\frac{1}{m_{r}+m}\left[-c_{1} \dot{x}-k_{1} x+m e\left(\ddot{\beta} \sin \beta+\dot{\beta}^{2} \cos \beta\right)+F_{x}+\right.$ $\boldsymbol{F}_{\boldsymbol{f} x}$

$$
\begin{aligned}
& \ddot{y}=\frac{1}{m_{r}+m}\left[-c_{1} \dot{y}-k_{1} y+m e\left(-\ddot{\beta} \cos \beta+\dot{\beta}^{2} \sin \beta\right)+\right. \\
& F_{y}+F_{f y}
\end{aligned}
$$

$$
\ddot{\Theta}=\frac{1}{j}\left[-c \dot{\Theta}-k \Theta+m e(\ddot{x} \sin \beta-\ddot{y} \cos \beta)+M_{t}\right]
$$

Planar motions of the rotor about $\mathrm{x}$ and $\mathrm{y}$ axes are expressed with lateral stiffness and equivalent damping coefficients along the corresponding axes. External forces $F_{x}$ and $F_{y}$ presents the tangential and normal forces and $M_{t}$ the external moments.

\section{A- Contact Forces}

When the rotor lateral displacement becomes higher than the clearance, the stator wall will induce normal and tangential forces due to dry friction between the two bodies. Normal restoring forces depend upon the relative rotor and stator deflection. It may be given by:

$F_{n}= \begin{cases}k_{s}(r-\delta) & r>\delta \\ 0 & r \leq \delta\end{cases}$

Where, the clearance $\boldsymbol{\delta}=\frac{\mathbf{1}}{\mathbf{2}}\left(\boldsymbol{D}_{\boldsymbol{s}}-\boldsymbol{D}_{\boldsymbol{r}}\right) \quad$ And, $\boldsymbol{r}=$ $\sqrt{x^{2}+y^{2}}$

Tangential friction force is produced by friction material and generated at the contact interface, takes a blocking action, since it is opposite to the rotary direction of rotor, and can be expressed as a function of friction coefficient and normal forces:

$$
F_{t}=\left\{\begin{array}{lc}
-\mu F_{n} & r \leq \delta \\
0 & r>\delta
\end{array}\right.
$$


External forces and moment, along $\mathrm{x}$ and $\mathrm{y}$ axis, can be concluded from the previous formulations:

$$
\begin{aligned}
& F_{x}=\frac{-\left(x F_{n}+y F_{t}\right)+F_{f x}}{r} \\
& F_{y}=\frac{x F_{t}-y F_{n}+F_{y x}}{r}
\end{aligned}
$$

Where Ffx and Ffy present the drill mud forces.

\section{B- Drill mud forces}

Derivation of fluid forces is based on the consideration that the fluid rotation plays an important role in the resulting dynamic phenomena and may a significant effort on rotor vibrations [15].

When the rotor is rotating, circumferential fully developed drill mud flow is assumed to be established. The rotating rate of the mud is approximated by $\lambda \Omega$, where $\Omega$ is the rotating speed and $\lambda$ is the mud velocity ratio which is close to a half. Considering the rotating reference coordinate $x-y$ the mud forces can be written as:

$$
\begin{aligned}
& {\left[\begin{array}{c}
F_{f x} \\
F_{f y}
\end{array}\right]=\left[\begin{array}{cc}
m_{f} & 0 \\
0 & m_{f}
\end{array}\right]\left[\begin{array}{c}
\ddot{x} \\
\ddot{y}
\end{array}\right]+\left[\begin{array}{cc}
D+\Psi_{2}(|z|) & 2 \lambda \Omega m_{f} \\
-2 \lambda \Omega m_{f} & D+\Psi_{2}(|z|)
\end{array}\right]\left[\begin{array}{c}
\dot{x} \\
\dot{y}
\end{array}\right]+} \\
& {\left[\begin{array}{cc}
k_{f}-\lambda^{2} \Omega^{2} m_{f}+\Psi_{1}(|z|) & \lambda \Omega\left(D+\Psi_{2}(|z|)\right) \\
-\lambda \Omega\left(D+\Psi_{2}(|z|)\right) & k_{f}-\lambda^{2} \Omega^{2} m_{f}+\Psi_{1}(|z|)
\end{array}\right]\left[\begin{array}{l}
x \\
y
\end{array}\right]}
\end{aligned}
$$

$\mathrm{D}$ is the mud friction coefficient, which is proportional to the rotation speed $\Omega$ since the tangential stiffness is generated by the relative velocity and radial damping. $\Psi i$ are a nonlinear functions related to the mud circumferential velocity. As a first approximation, only the symmetric terms will be considered.

Considering equations of motions, friction interaction model and drill mud forces, mathematical model was developed. Respecting the system parameters mentioned in Table.1, numerical simulation was carried.

TABLE I. SYSTEM PARAMETERS VALUES USED FOR NUMERICAL STUDIES

\begin{tabular}{|c|c|c|}
\hline Parameter & Value & Units \\
\hline$D_{r}$ & 0.16 & $m$ \\
\hline$D_{s}$ & 0.19 & $\mathrm{~m}$ \\
\hline$m_{r}$ & 0.9 & $\mathrm{~kg}$ \\
\hline$m$ & 0.068 & $\mathrm{~kg}$ \\
\hline$m_{f}$ & 1.2 & $\mathrm{~kg}$ \\
\hline$D$ & 0.1 & $\mathrm{~ms}$ \\
\hline$L$ & $2 e 3$ & $\mathrm{Nm}$ \\
\hline$K$ & 1 & N.ms.rad-1 \\
\hline$c$ & $1.83 \mathrm{e}^{-4}$ & Rad.s -1 \\
\hline$\Omega$ & $\Omega=5.23(2 \pi)-$ & \\
\hline
\end{tabular}

\section{Comparisons amongst Experimental results and Numerical Predictions}

\section{A- Experimental arrangement}

To simulate the working conditions experienced by drill string, a llaboratory scaled drilling apparatus has been constructed as presented in Fig.3.
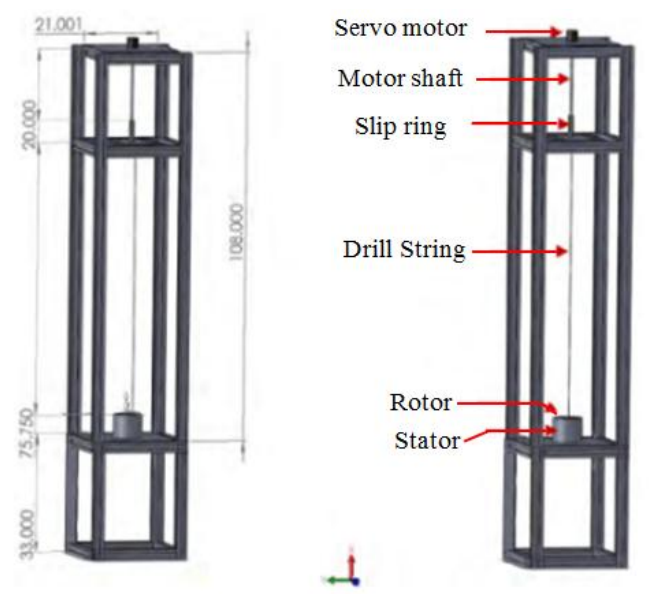

Figure 3. 3D Design of the experimental apparatus

The BHA was modeled by an aluminum rigid disk, the borehole by a rigid cylinder and the drill string by a long aluminum shaft. The upper end of the shaft, was driven by a powered and controlled servo- motor. An unbalanced mass is attached to the rotor to excite lateral motions.

Data are gathered through several means. Accelerometers fixed on the rotor chuck and following $\mathrm{x}$ $\mathrm{y}$ lateral directions as illustrated in Fig4. Strain gages are securely fixed on the drill string to capture torsional vibrations. Bentonite water based drill mud annulus surrounding the rotating cylinder was prepared as per well drilling industries.

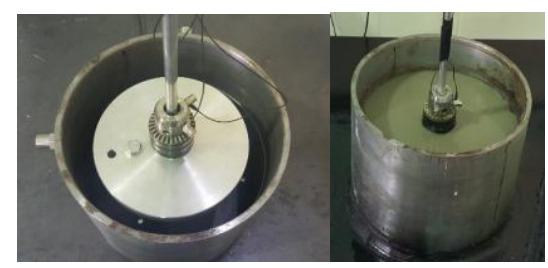

Figure 4. Experimental arrangement of scale drilling apparatus with and without drilling mud 
Proc. of the Sixth Intl. Conf. Advances in Civil, Structural and Mechanical Engineering - CSM 2018

Copyright (C) Institute of Research Engineers and Doctors, USA. All rights reserved.

ISBN: 978-1-63248-150-4 doi: 10.15224/978-1-63248-150-4-48

While in operation, rotor lateral acceleration, velocity and displacement time histories are recorded for 'Low' and 'high' velocities to provide data on fluid damping effect depending on rotating speed.

Rotor whirl orbits for high and low drive speeds are shown in Fig.5. The transition from a circular orbit in to a thin orbit is due to the increase of drive speed. Lower radial spread closer to the center of the stator is observed for low speed. This qualitative change in system dynamics has an important implication to use the drive speed as a control parameter to avoid undesirable bouncing and impacting motions that can cause stick-slip vibrations.

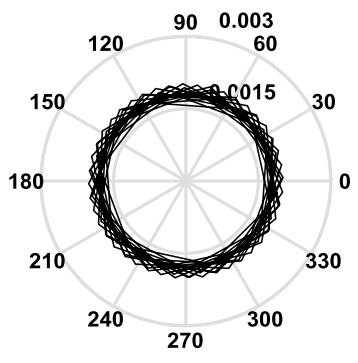

(1)

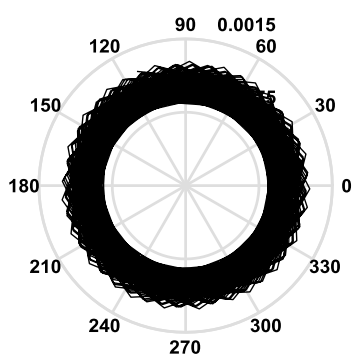

(3)

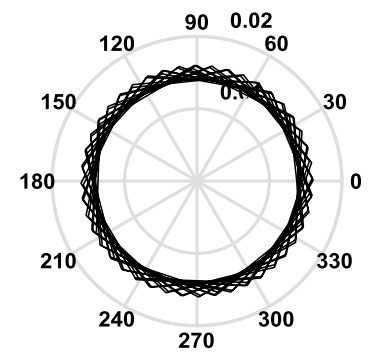

(2)

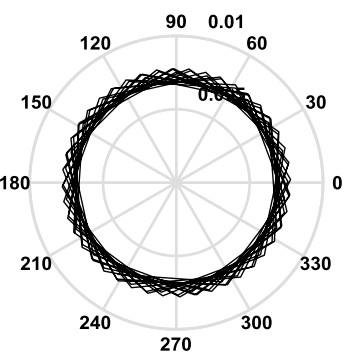

(4)
Figure 5. Comparison between simulation and experimental results of rotor trajectory with respect to drive speed: (1) experiments of rotor Orbit at $\Omega=5.23(2 \pi)$ (2) simulation of rotor Orbit at $\Omega=5.23(2 \pi)$ (3) experiments of rotor Orbit at

$\Omega=10.47(2 \pi)$ simulation of rotor Orbit at $\Omega=10.47(2 \pi)$

To understand the smoothed oscillation with respect to drive speed, and the mud damping effect, stator-fluid forces are compared for low and drive speeds as shown in Fig.6.

For high rotating speed, the mud forces are much higher which is related to the damping effect of the mud hydrodynamic mass. However these force are unstable comparing to the fluid forces at low drive speed.

In fact, at low rotor speeds, the Reynold number is low and the fluid velocity across the thickness of a thin annulus varies from the rotor velocity to zero velocity at the stator edge. The flow is called 'laminar Couette' flow. When the drive speed is decreased this flow becomes unstable due to the centrifugal forces. This flow is called 'Vortex flow' in which a component appear as a ring in the fluid annulus. In a thin layer close to the rotor the fluid velocity becomes equal to the rotor velocity [17]. These phenomena is captured in Fig.8. However this conversion of fluid flow, which is related to the drive speed, is a reaction to the rotor deflection. As defined in Ref. [17] the average fluid velocity, at the thin annulus, in this case is considered to be $: v=\Omega R / 2+V$, where $\mathrm{V}$ is related to the deflection. This confirm the results obtained in Fig. 5. Fluid forces are following the radial spread of the rotor in order to quench the nonlinear vibrations. Rotor is rotating in a thinner annular orbit and whirl harmful vibration are avoided.
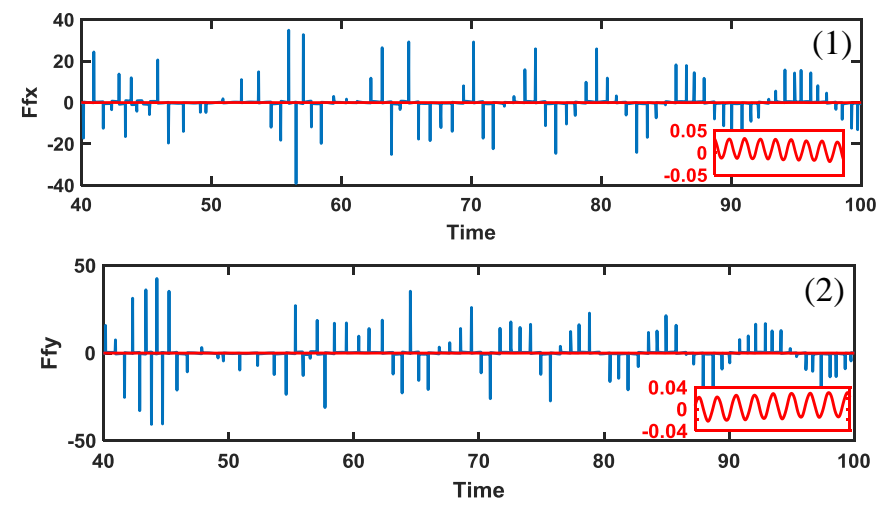

Figure 6. Simulation of drilling mud forces for $\Omega=5.23(2 \pi)$ $\mathrm{rad} / \mathrm{s}$ (red) and $\Omega=10.47(2 \pi) \mathrm{rad} / \mathrm{s}$ (blue)
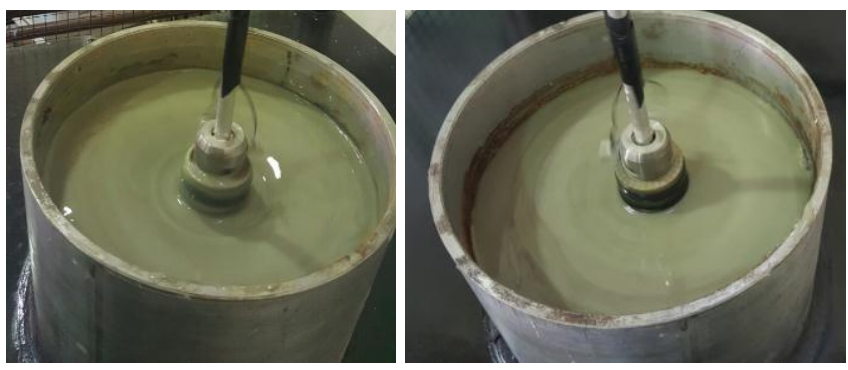

Figure 7. Experimental observation of rotor motions illustrating system behavior at (1) low $(\Omega=5.23(2 \pi) \mathrm{rad} / \mathrm{s})$ and high $(10.47(2 \pi) \mathrm{rad} / \mathrm{s})$

Rotor vibrational amplitude at both speeds was digitally filtered by using a third-order, low-pass Butterworth filter with a $20 \mathrm{~Hz}$ cut-off frequency. Power density spectra are presented in Fig.7. At low drive speed, $\Omega=5.23(2 \pi) \mathrm{rad} / \mathrm{s}$ $(0.83 \mathrm{~Hz})$, peaks are observed at drive speed, maintaining a $\times 1$ ratio with it. Fluid effect can be seen along with rotor synchronous vibration response. At high drive speed, synchronous vibration represents a small fraction of vibration response and drill mud dynamic effects clearly dominate.

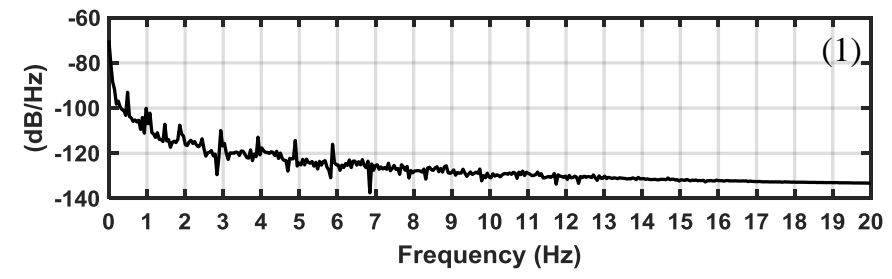




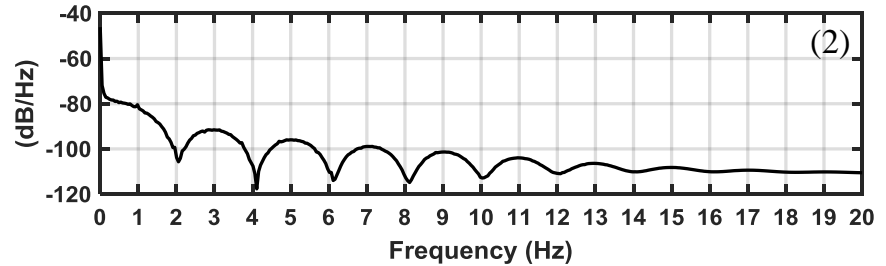

Figure 8. Power spectrum density obtained from experiments of rotor center displacement with respect to drive speed (1) at $\Omega=5.23(2 \pi) \mathrm{rad} / \mathrm{s},(2) \Omega=10.47(2 \pi) \mathrm{rad} / \mathrm{s}$

\section{Iv. Concluding Remarks}

In this paper, the authors have presented a modified Jeffcott rotor focusing on bit-rock nonlinear interactions. Attention was paid to effect of drive speed on drill mud damping forces. Simulations were carried out based on nonlinear differential equations considering friction and mud forces. Resulting rotor responses were compared for low and high drive speeds. The findings suggest that the damping effects of the drill mud is increased with deflected rotor as the mud velocity become proportional to the deflection value. Dominance of the drilling fluid dynamics at high drive speed was also observed on the rotor frequency responses. Further improvement of the current work under consideration include modification of the fluid forces interaction model considering the fluid dynamic and flow variation on the annular clearance.

\section{Acknowledgment}

This work was made possible by NPRP grant \# [7-083-2041] from the Qatar National Research Fund (a member of Qatar Foundation). The statements made herein are solely the responsibility of the authors.

\section{References}

[1] R. Caenn and G.V. Chillinger, "Drilling fluids: state of the art," J. Pet. Sci. Eng, Vol. 14, pp- 221-230.

[2] T. Whittington and A.O. De Weegh, "Penetration rates optimized by Aligning Torque and Rotary speed,", J. Oil\& Gas, Vol. 97, pp- 55-57.

[3] J.J. Bailey and I. Finnie, "An analytical study of drillstring vibration," Trans. J. Eng. Ind., Vol.82, pp. 122-28, 1960.

[4] M. Denny, "Stick-slip motion: an important example of self-excited oscillation" Eur. J. Phys. Vol.25, pp. 311-22.2004.

[5] A. Berlioz, D. Der Hagopian, J.R. Dufour and E. Draoui, " Dynamic behaviour of a drill-string: experimental investigation of lateral instabilities," J. Vib. Acoust. acoustics vol.118,pp. 292-98, 1996.

[6] K.A. Macdonald, J.V. Bjune, "Failure analysis of drill strings, Engineering Failure Analysis" Vol. 14, pp.1641-1666, 2004.

[7] E. Navarro-Lopez and D. Cortes, "Sliding-mode of a multi-DOF oil well drillstring with stick-slip oscillations". Proc. Am. Cont. Conf. New York City, USA, 3837-42.2007.

[8] P. Sauoikone, , O. Kmorhlmaand and D. white, "A Field Method for Controlling Drillstring Torsional Vibrations," IADCLSPE Drilling Conf. Louisiana, pp. 43-45, 1992.

[9] P.A. Patil and C. Teodoriu, "Model development of torsional drillstring and investigating parametrically the stick-slips influencing factors," J. Energy Resour. Technol. Vol 135 (1), pp. 1-7.2012.

[10] J.D. Jansen, "Nonlinear Dynamics of Oil Well Drillstrings," Delft University Press. 1993.
[11] S.J. Cull, R.W. Tucker, "On the modeling of coulomb friction," J. Phys. A, Math. Gen. Vol. 32, pp. 2103-2113.1999.

[12] D. Zhao, S. Hovda and S. Sangesland. "The effect of stick slip vibration on the Backward Whirl Of Bottom Hole Assembly in Drillstring." Proc. ASME 2016, 35th Int.Conf. on Ocean, Offshore \& Arctic Eng. Korea, OMAE2916-54478.2016.

[13] M. Kanzari, M. AlQaradawi, and B. Balakumar, "Experimental Studies with Drill String: Effects of Drill Mud, "9th Eur. Nonlinear Dyn. Conf. ENOC, Nonlinear Phenomena in Mechanical and Structural Systems. Hungary. pp. 337-372., June, 2017.

[14] N. Vlajic, X. Liu, H. Karki and B. Balachandran, "Torsional Oscillations of a Rotor with Continuous Stator Contact.” Int. J. Mech. Sci. Vol. 83 pp. 65-75, 2014.

[15] H.F. Black and D.N. Jensen, "Dynamic hybrid bearing characteristics of annular controlled leakage seal," Proc. J. Mech. Eng. Vol.184. pp. 92100.1970 .

[16] A. Muszynska, "Whirl and whip rotor/ bearing stability problems," J. Sound Vib., Vol.110, pp. 443-462, 1986.

[17] R.J. Fritz, "The Effects of an Annular Fluid on the Vibrations of a Long Rotor, Part 1-Theory," J. Basic Eng. Vol. 92, pp.923-929, 1970. 